\title{
Incidence, number and topography of Wormian bones in Greek adult dry skulls
}

\author{
K. Natsis ${ }^{1}$, M. Piagkou ${ }^{2}$, N. Lazaridis ${ }^{1}$, N. Anastasopoulos ${ }^{1}$, G. Nousios ${ }^{1}$, \\ G. Piagkos'², M. Loukas ${ }^{3}$ \\ ${ }^{1}$ Department of Anatomy, Faculty of Health and Sciences, Medical School, Aristotle University of Thessaloniki, Greece \\ ${ }^{2}$ Department of Anatomy, Medical School, National and Kapodistrian University of Athens, Greece \\ ${ }^{3}$ Department of Anatomical Sciences, School of Medicine, St. George's University, Grenada, West Indies
}

[Received: 19 January 2018; Accepted: 7 March 2018]

Background: Wormian bones (WBs) are irregularly shaped bones formed from independent ossification centres found along cranial sutures and fontanelles. Their incidence varies among different populations and they constitute an anthropological marker. Precise mechanism of formation is unknown and being under the control of genetic background and environmental factors. The aim of the current study is to investigate the incidence of WBs presence, number and topographical distribution according to gender and side in Greek adult dry skulls.

Materials and methods: All sutures and fontanelles of 166 Greek adult dry skulls were examined for the presence, topography and number of WBs. One hundred and nineteen intact and 47 horizontally craniotomised skulls were examined for WBs presence on either side of the cranium, both exocranially and intracranially.

Results: One hundred and twenty-four (74.7\%) skulls had WBs. No difference was detected between the incidence of WBs, gender and age. Sutures and fontanelles located in neurocranium showed a higher incidence of WBs, contrariwise to orbital sutures that indicated a low incidence. WBs most commonly located in the lambdoid suture (44.6\%), followed in order of frequency by the coronal suture (39.8\%), asterion (21\% on the left and $15.3 \%$ on the right side) and parietomastoid suture (15.1\% on the left and $13.9 \%$ on the right side). Other sutures with WBs were the occipitomastoid, sagittal, squamosal, zygomaticosphenoid, metopic, frontonasal and frontozygomatic. Regarding the skull fontanelles, WBs were found at pterion, posterior and anterior fontanelles.

Conclusions: The current study highlights a high incidence of WBs in a Greek population, indicating racial variation. The in depth knowledge of exact location, frequency and number of WBs is essential for clinicians intervening in the skull area, anthropologists and forensic surgeons investigating child abuse cases. (Folia Morphol 2019; 78, 2: 359-370)

Key words: Wormian bones, sutural bones, fontanelle, skull asymmetry, variation, syndrome, deformation 


\section{INTRODUCTION}

Wormian bones (WBs) or sutural bones or supernumerary bones or ossicles, are irregularly shaped bones formed from independent ossification centres found along cranial sutures and fontanelles [17]. These ossicles may appear on both the outer and inner tables of the skull, or exclusively on either table. They joined with the surrounding bones by particularly complex sutures and appear with a variable size, number and shape in different locations [3].

Although two main hypotheses have been proposed to explain their formation, the precise mechanism still remains unknown. The first hypothesis considers that WBs are under genetic influence [13]. Bennett [4] supported that WBs are inherited as dominant traits, Finkel [13] suggested that their formation is the result of a single gene expression and Mao et al. [21] mentioned that their formation is under the epigenetic control of traits. The second hypothesis considers mechanical stress (artificial cranial deformation or craniosynostosis), as the main reason for WBs formation [13, 26, 31]. Another hypothesis [11, 26, 31] suggests that genetic factors influence WBs appearance, while the mechanical stress has an impact on their number.

Although WBs can be found in healthy individuals, they may also be observed in patients with a variety of congenital disorders, like osteogenesis imperfecta, cretinism, cleidocranial dysostosis and enlarged parietal foramina $[23,24,28]$, as well as in patients with central nervous system abnormalities [29]. Their incidence varies among different populations and therefore these bones constitute an anthropological marker.

The aim of the current study is to investigate the incidence of WBs, number and topographical distribution according to gender and side in a population of Greek adult skulls, both intracranially and exocranially.

\section{MATERIALS AND METHODS}

One hundred and sixty-six (92 males and 74 females) Greek dry human skulls of known age from the osteological collection of the Department of Anatomy and Surgical Anatomy (Medical School of Aristotle University of Thessaloniki) and the Department of Anatomy (Medical School of National and Kapodistrian University of Athens) were examined. The skulls, which belonged to body donators after informed consent, were separated into three age subgroups: $20-39$ years old $(n=41)$, $40-59(n=30)$ and over 60 years $(n=95)$. Skulls of children, those with deformities (occipital flattening, syndromic background and asymmetries), obvious pathological conditions (trauma or bone disease) and craniosynostosis were excluded. Our sample comprised 119 intact and 47 horizontally craniotomised skulls which were examined for WBs presence on either side of the cranium, both exocranially and intracranially. From an embryological point of view, the skull is composed of the neurocranium and viscerocranium which derive from the mesoderm and neural crest [2]. The orbit is formed from both of them. Thus, we observed all sutures and fontanelles in viscerocranium, orbit and neurocranium and recorded WBs presence, topographic location and number of WBs, by visual inspection, in order to determine which part of the skull presented the higher incidence of WBs. In our study, only the bones surrounded by apparent sutures were recorded as WBs and only the obvious ones were counted. Inca bones were ignored, since their developmental background is different. Correlation of WBs presence with gender and age was investigated using the $\chi^{2}$ test. Side asymmetry was further examined with McNemar test. Statistical analysis was carried out using IBM SPSS Statistics for Windows version 21.0.

\section{Ethical approval}

The performed investigation in dry human skulls of Greek population was in accordance with the ethical standards of the Ethical Committee of our Institutions and with the 1964 Helsinki declaration and its later amendments or comparable ethical standards.

\section{RESULTS}

One hundred and twenty-four (74.7\%) dry skulls had WBs. No significant difference was detected between the incidence of WBs, gender and age. Sutures and fontanelles located in neurocranium showed a higher incidence of WBs (Tables 1-4); while a low incidence of WBs was found in the majority of the orbital sutures (Tables 2,4). WBs most commonly located in the lambdoid suture (LS) (44.6\%) (Figs. 1, 2), followed, in order of frequency, by the coronal suture (CS) (39.8\%) (Fig. 3), asterion (21\% on the left and

Table 1. Wormian bones (WBs) presence and absence in Greek skulls according to gender

\begin{tabular}{lccc}
\hline Gender & $\mathbf{N}(\%)$ & WBs presence & Absence \\
\hline Male & $92(55.4 \%)$ & $67(72.8 \%)$ & $25(27.2 \%)$ \\
Female & $74(44.6 \%)$ & $57(77 \%)$ & $17(23 \%)$ \\
Total & 166 & $124(74.7 \%)$ & $42(25.3 \%)$ \\
\hline
\end{tabular}


Table 2. Exocranial topographical distribution and frequency of Wormian bones (WBs) according to side

\begin{tabular}{|c|c|c|c|c|c|c|}
\hline WBs located at & $\begin{array}{c}\text { Range of } \\
\text { observed WBs } \\
\text { (min-max) }\end{array}$ & \multicolumn{2}{|c|}{ Side } & $\begin{array}{l}\text { Number of } \\
\text { skulls }\end{array}$ & $\begin{array}{l}\text { Frequency over } \\
\text { the total number } \\
\text { of skulls }\end{array}$ & $\begin{array}{l}\text { Frequency over } \\
\text { the number of } \\
\text { skulls with WBs }\end{array}$ \\
\hline Lambdoid suture (LS) & $1-18$ & & & 74 & $74 / 166(44.6 \%)$ & $74 / 124(59.7 \%)$ \\
\hline Parietomastoid suture (PMS) & $1-6$ & $23 \mathrm{R}(18.5 \%)$ & $25 \mathrm{~L}(20.2 \%)$ & 48 & 48/166 (28.9\%) & 48/124 (38.7\%) \\
\hline Occipitomastoid suture (OMS) & $1-7$ & $11 \mathrm{R}(8.9 \%)$ & $8 \mathrm{~L}(6.5 \%)$ & 16 & $16 / 166(9.63 \%)$ & $16 / 124(12.9 \%)$ \\
\hline Sagittal suture (SS) & 1-5 and multiple & & & 18 & $18 / 166(10.8 \%)$ & 18/124 (14.5\%) \\
\hline Coronal suture (CS) & 1-21 and multiple & & & 66 & $66(39.8 \%)$ & $66 / 124(53.2 \%)$ \\
\hline Squamosal suture (SOS) & $1-5$ & $12 \mathrm{R}(9.7 \%)$ & $9 \mathrm{~L}(7.3 \%)$ & 21 & $21 / 166(12.7 \%)$ & $21 / 124(16.9 \%)$ \\
\hline Metopic suture (MS) & 1 & & & 1 & $1 / 166(0.6 \%)$ & $1 / 124(0.8 \%)$ \\
\hline Frontonasal suture (FNS) & 1 & & & 1 & $1 / 166(0.6 \%)$ & $1 / 124(0.8 \%)$ \\
\hline Asterion (Ast) & $1-8$ & $19 R(15.3 \%)$ & $26 \mathrm{~L}(21 \%)$ & 38 & $38 / 166(22.9 \%)$ & $38 / 124(30.6 \%)$ \\
\hline Pterion (Pt) & $1-2$ & $6 \mathrm{R}(4.8 \%)$ & $4 \mathrm{~L}(3.2 \%)$ & 9 & $9 / 166(5.4 \%)$ & 9/124 (7.25\%) \\
\hline Anterior fontanelle (AF) & $1-2$ & & & 2 & $2 / 166(1.2 \%)$ & $2 / 124(1.6 \%)$ \\
\hline Posterior fontanelle (PF) & $1-2$ & & & 3 & $3 / 166(1.8 \%)$ & $3 / 124(2.4 \%)$ \\
\hline Frontal bone (FB) & 1 & & & 2 & $2 / 166(1.2 \%)$ & $2 / 124(1.6 \%)$ \\
\hline Frontonasal suture (FNS) & 1 & & & 1 & $1 / 166(0.6 \%)$ & $1 / 124(0.8 \%)$ \\
\hline Sphenoid bone (SB) & 1 & & & 2 & $2 / 166(1.2 \%)$ & $2 / 124(1.6 \%)$ \\
\hline Zygomatosphenoid suture* (ZMSS) & $1-4$ & $4 \mathrm{R}(3.2 \%)$ & $2 \mathrm{~L}(1.6 \%)$ & 4 & $4 / 166(2.4 \%)$ & $4 / 124(3.2 \%)$ \\
\hline Frontozygomatic suture (FZMS) & $\begin{array}{c}1-4 \text { intraorbital } \\
1 \text { extraorbital }\end{array}$ & $\begin{array}{c}4 \mathrm{R}(3.2 \%) \\
1 \mathrm{R}\end{array}$ & $\begin{array}{c}1 \mathrm{~L}(0.8 \%) \\
-\end{array}$ & $\begin{array}{l}3 \\
1\end{array}$ & $\begin{array}{l}3 / 166(1.8 \%) \\
1 / 166(0.6 \%)\end{array}$ & $\begin{array}{l}3 / 124(2.4 \%) \\
1 / 124(0.8 \%)\end{array}$ \\
\hline Sphenofrontal suture (SFS) & 2 intraorbital & - & $2 \mathrm{~L}(1.6 \%)$ & 2 & $2 / 166(1.2 \%)$ & $2 / 124(1.6 \%)$ \\
\hline Frontolacrimal suture* (FLS) & 1 & - & $1 \mathrm{~L}(0.8 \%)$ & 1 & $1 / 166(0.6 \%)$ & $1 / 124(0.8 \%)$ \\
\hline Zygomatomaxillary suture* (ZMMS) & $1-2$ & $1 \mathrm{R}(0.8 \%)$ & $2 \mathrm{~L}(1.6 \%)$ & 1 & $1 / 166(0.6 \%)$ & $1 / 124(0.8 \%)$ \\
\hline Sphenomaxillary suture* (SMS) & 1 & & $1 \mathrm{~L}(0.8 \%)$ & 1 & $1 / 166(0.6 \%)$ & $1 / 124(0.8 \%)$ \\
\hline Lacrimomaxillary suture* (LMS) & 1 & & & 1 & $1 / 166(0.6 \%)$ & $1 / 124(0.8 \%)$ \\
\hline Sphenozygomatic suture* (SZMS) & $1-3$ & $3 \mathrm{R}(2.4 \%)$ & $1 \mathrm{~L}(0.8 \%)$ & 4 & $4 / 166(2.4 \%)$ & $4 / 124(3.2 \%)$ \\
\hline
\end{tabular}

*Intraorbital location; L — left side; R — right side

$15.3 \%$ on the right side) (Fig. 4) and parietomastoid suture (PMS) $(15.1 \%$ on the left and $13.9 \%$ on the right side) (Fig. 5). WBs were also detected in the occipitomastoid (OCMS) (Fig. 6), sagittal (SS) (Fig. 7), squamosal (SQS) (Fig. 8), zygomaticosphenoid (ZMSS), metopic (MS), frontonasal (FNS) (Fig. 9) and frontozygomatic suture (FZMS) (Fig. 10). As regards the skull fontanelles, WBs appeared at pterion (Fig. 11), posterior and anterior fontanelle (PF and AF) (Fig. 12; Tables 1-4). Another remarkable point was the presence of a single WB in the frontal bone (FB) (2 skulls) and sphenoid bone (SB) (2 skulls) (Fig. 13). Regarding the craniotomised skulls (44 out of 47 ), an incidence of $93.6 \%$ had WBs and 21 out of 47 , an incidence of $44.7 \%$ were detected with WBs intracranially. WBs were located into the LS, asterion, CS, PMS, SS, SQS, $F B$, SB (greater wing), OCMS, pterion, SPS, SFS, AF and PF (Figs. 13-15).
The number of WBs in each suture demonstrated a wide range. $L S$ and $C S$ presented the higher number of WBs (1-18) (Figs. 3, 14, 15) and (1-21 and multiple), respectively. An interesting observation was that all WBs in the LS were larger than $1 \mathrm{~cm}$, while in the CS were smaller than $0.5 \mathrm{~cm}$ in $95.32 \%$ of the skulls. Taking into account the laterality - side asymmetry of WBs presence, our analysis concluded that a statistically significant difference existed only in the asterion $(p=0.04)$ with a right side dominance.

\section{DISCUSSION}

Wormian bones are joined with the surrounding bones by particularly complex sutures, especially on the outer table of the skull. They are located along cranial sutures and fontanelles, originating from independent ossification centres $[1,17]$. These ossicles possess a variable size and shape, being ectopic is- 
Table 3. Intracranial topographical distribution and frequency of Wormian bones (WBs) according to side

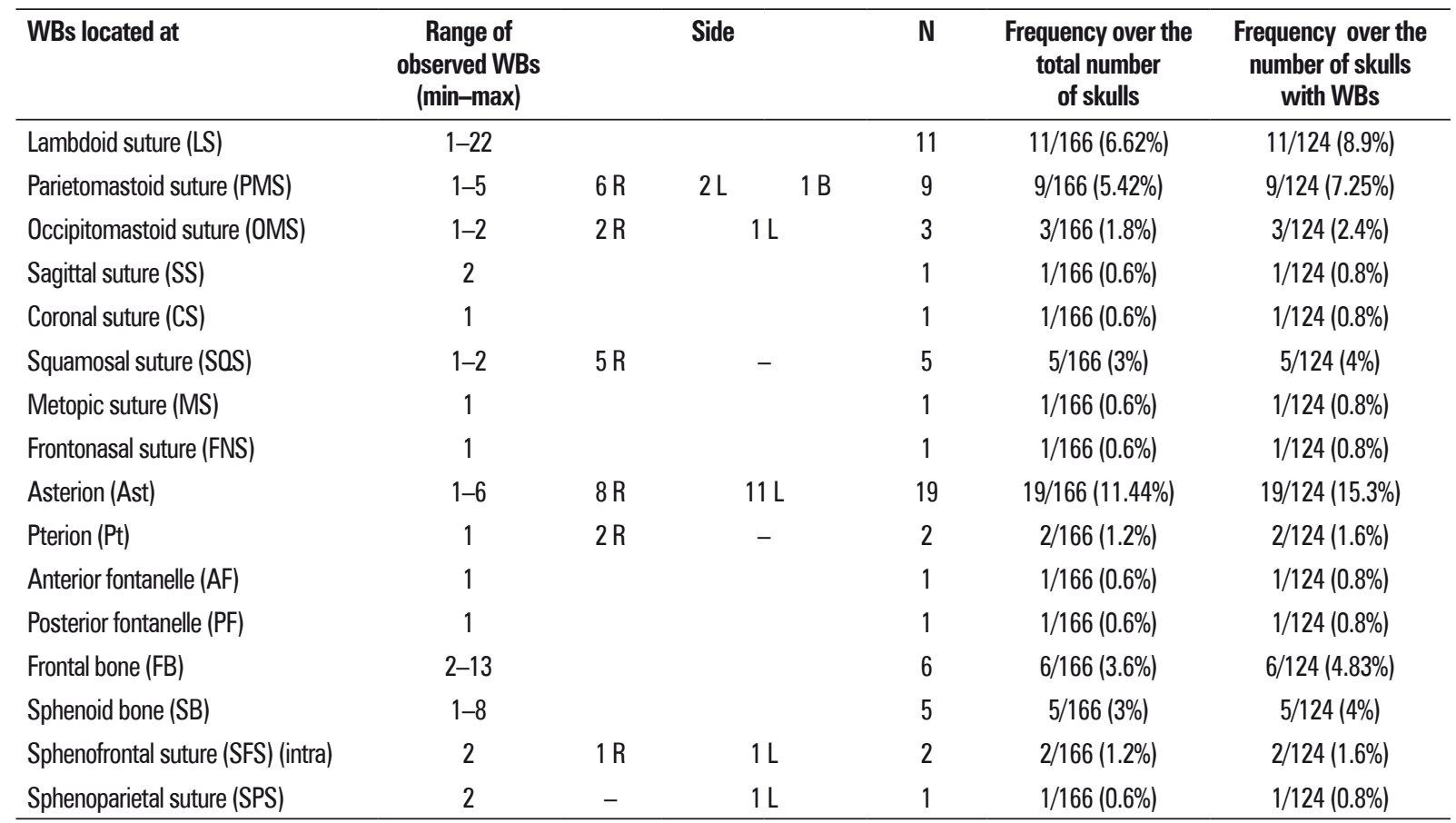

$\mathrm{B}$ - bilaterally; L — left side; $\mathrm{N}$ - number of skulls; $\mathrm{R}$ - right side

Table 4. Exocranial topographical distribution and frequency of Wormian bones (WBs) according to gender (males and females) and sides (right $[R]$ and left $[L]$ )

\begin{tabular}{|c|c|c|c|c|c|c|c|}
\hline \multirow[t]{2}{*}{ WBs located at } & \multirow{2}{*}{$\begin{array}{l}\text { Range of observed WBs } \\
\text { (min-max) }\end{array}$} & \multicolumn{6}{|c|}{ Number of skulls and frequency (\%) } \\
\hline & & \multicolumn{2}{|c|}{ Males } & \multicolumn{2}{|c|}{ Females } & \multicolumn{2}{|c|}{ Total } \\
\hline Lambdoid suture (LS) & $1-18$ & \multicolumn{2}{|c|}{$40(43.5 \%)$} & \multicolumn{2}{|c|}{$34(45.9 \%)$} & \multicolumn{2}{|c|}{$74(44.6 \%)$} \\
\hline Parietomastoid suture (PMS) & $1-6$ & $16 R$ & $16 \mathrm{~L}$ & $7 \mathrm{R}$ & $9 \mathrm{~L}$ & $23 \mathrm{R}$ & $25 \mathrm{~L}$ \\
\hline Occipitomastoid suture (OMS) & $1-7$ & $10 \mathrm{R}$ & $6 \mathrm{~L}$ & $1 \mathrm{R}$ & $2 \mathrm{~L}$ & $11 \mathrm{R}$ & $8 \mathrm{~L}$ \\
\hline Sagittal suture (SS) & $1-5$ and multiple & \multicolumn{2}{|c|}{$9(9.8 \%)$} & \multicolumn{2}{|c|}{$9(12.2 \%)$} & \multicolumn{2}{|c|}{$18(10.8 \%)$} \\
\hline Coronal suture (CS) & 1-12 and multiple & \multicolumn{2}{|c|}{$39(42.4 \%)$} & \multicolumn{2}{|c|}{$27(36.5 \%)$} & \multicolumn{2}{|c|}{$66(39.8 \%)$} \\
\hline Squamosal suture (SOS) & $1-5$ & $7 \mathrm{R}$ & $4 \mathrm{~L}$ & $5 R$ & $5 \mathrm{~L}$ & $12 \mathrm{R}$ & $9 \mathrm{~L}$ \\
\hline Frontonasal suture (FNS) & 1 & \multicolumn{2}{|c|}{-} & \multicolumn{2}{|c|}{$1(1.4 \%)$} & \multicolumn{2}{|c|}{$1(0.8 \%)$} \\
\hline Metopic suture (MS) (1WB) & 1 & \multicolumn{2}{|c|}{$1(1.1 \%)$} & \multicolumn{2}{|c|}{-} & \multicolumn{2}{|c|}{$1(0.8 \%)$} \\
\hline Asterion (Ast) & $1-10$ & $15 R$ & $17 \mathrm{~L}$ & $4 R$ & $9 \mathrm{~L}$ & $19 R$ & $26 \mathrm{~L}$ \\
\hline Pterion (Pt) & $1-2$ & $2 \mathrm{R}$ & $2 \mathrm{~L}$ & $4 R$ & $2 \mathrm{~L}$ & $6 \mathrm{R}$ & $4 \mathrm{~L}$ \\
\hline Anterior fontanelle (AF) & $1-2$ & \multicolumn{2}{|c|}{$2(2.2 \%)$} & \multicolumn{2}{|c|}{-} & \multicolumn{2}{|c|}{$2(1.6 \%)$} \\
\hline Posterior fontanelle (PF) & $1-2$ & \multicolumn{2}{|c|}{$1(1.1 \%)$} & \multicolumn{2}{|c|}{$2(2.8 \%)$} & \multicolumn{2}{|c|}{$3(2.4 \%)$} \\
\hline Frontal bone (FB) (extra) & 1 & \multicolumn{2}{|c|}{$1(1.1 \%)$} & \multicolumn{2}{|c|}{$1(1.4 \%)$} & \multicolumn{2}{|c|}{$2(1.6 \%)$} \\
\hline Sphenoid bone (SB) (extra) & 1 (exocranial) & \multicolumn{2}{|c|}{$2(2.2 \%)$} & \multicolumn{2}{|c|}{-} & \multicolumn{2}{|c|}{$2(1.6 \%)$} \\
\hline Zygomatosphenoid suture (ZMSS) & $1-4$ & $2 \mathrm{R}$ & $1 \mathrm{~L}$ & $2 \mathrm{R}$ & $1 \mathrm{~L}$ & $4 R$ & $2 \mathrm{~L}$ \\
\hline Frontozygomatic suture (FZMS) intraorbitally & $1-4$ & $4 \mathrm{R}$ & $1 \mathrm{~L}$ & - & - & $4 \mathrm{R}$ & $1 \mathrm{~L}$ \\
\hline Sphenofrontal suture (SFS) intracranially & 1 & - & - & - & $2 \mathrm{~L}$ & & $2 \mathrm{~L}$ \\
\hline Frontolacrimal suture (FLS) & 1 & - & $1 \mathrm{~L}$ & - & - & & $1 \mathrm{~L}$ \\
\hline Zygomatomaxillary suture (ZMMS) & $1-2$ & - & $1 \mathrm{~L}$ & $1 \mathrm{R}$ & $1 \mathrm{~L}$ & $1 \mathrm{R}$ & $2 \mathrm{~L}$ \\
\hline Sphenomaxillary suture (SMS) & 1 & - & - & - & $1 \mathrm{~L}$ & & $1 \mathrm{~L}$ \\
\hline Lacrimomaxillary suture (LMS) & 1 & & & & & & \\
\hline Sphenozygomatic suture (SZMS) & $1-3$ & $1 \mathrm{R}$ & - & $2 \mathrm{R}$ & $1 \mathrm{~L}$ & $3 R$ & $1 \mathrm{~L}$ \\
\hline
\end{tabular}




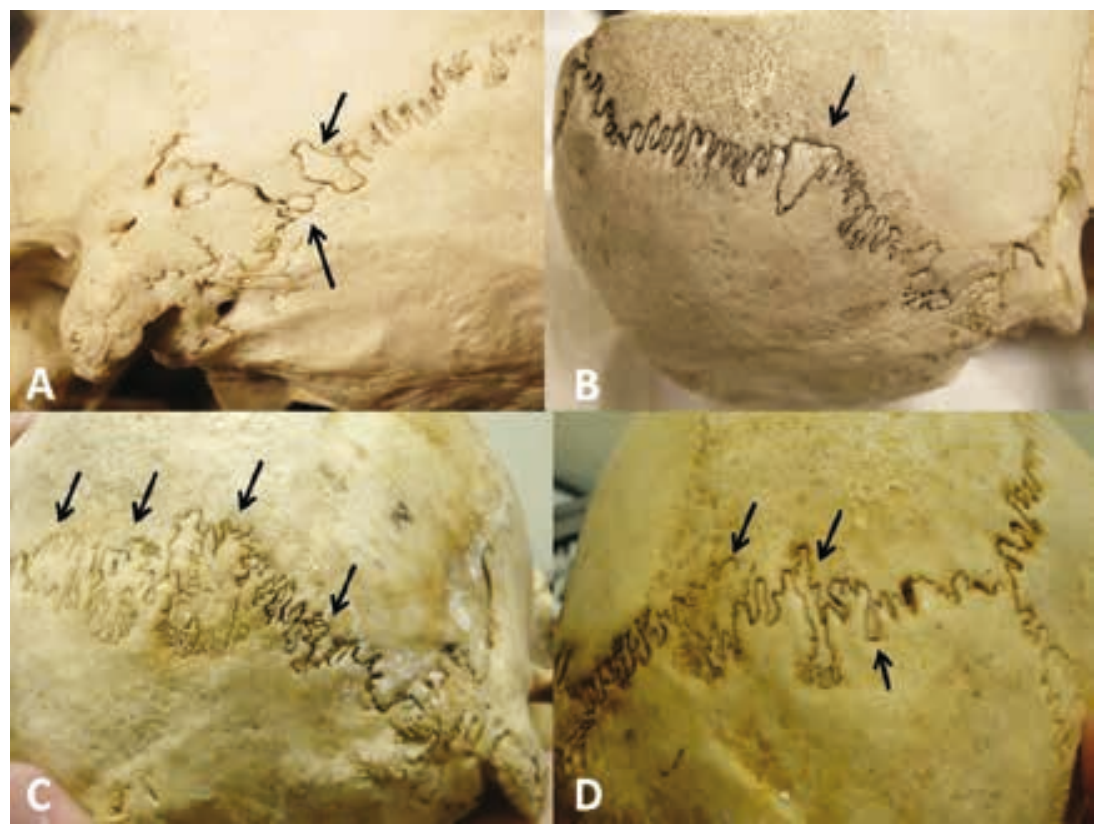

Figure 1. Wormian bones (WBs) in lambdoid suture; A. On the left side and asterion; B. On the right side, a WB of triangular shape; $\mathbf{C}$. Multiple right-sided WBs; $\mathbf{D}$. Various shapes of left-sided WBs.

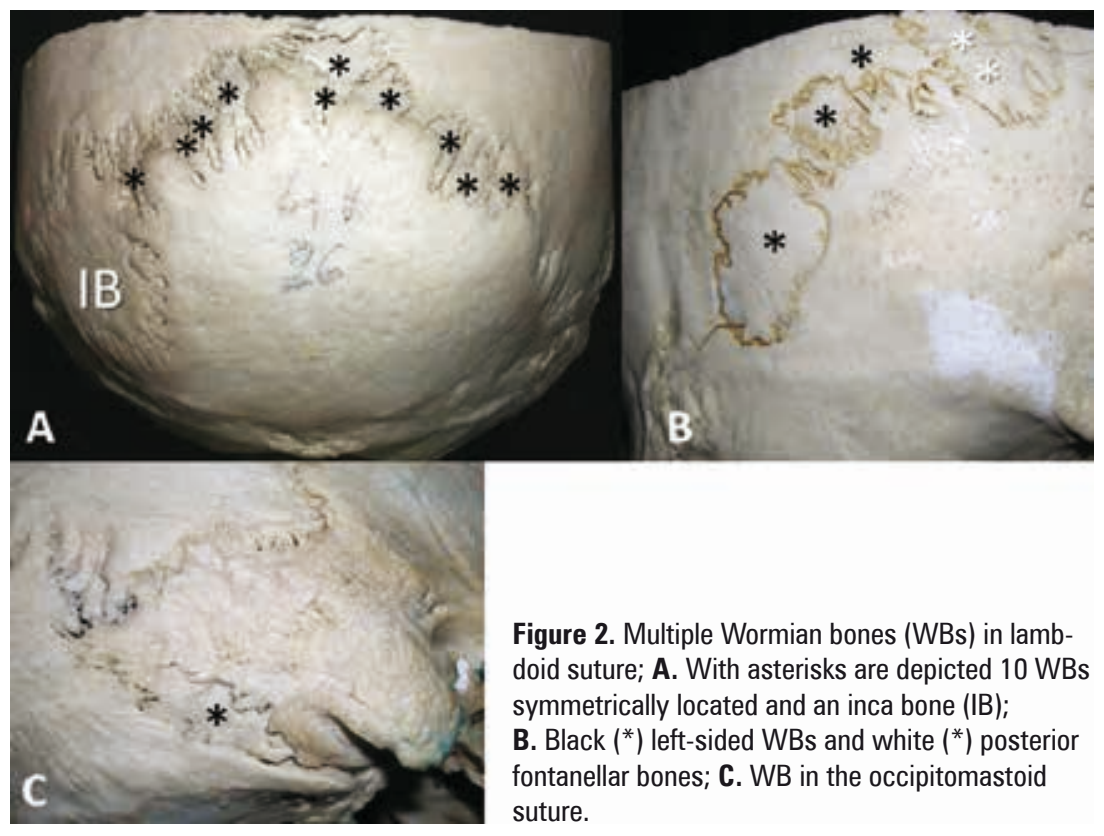

lands of intramembranous ossification. In foetuses, they are composed of a single layer of compact bone on the dural side, since diploe is not formed yet [19]. Mechanical factors increasing sutural width may trigger WBs formation [6]. The study of El-Najjar and Dawson [11] confirms the hypothesis of genetic influence in WBs development, since they appeared in foetal skulls, with reduced environmental stressing factors. Cranial deformation either cultural or after craniosynostosis affects the frequency and location of certain types of WBs [1, 26, 31]. When WBs appear as a normal variant, they have usually smaller dimensions and number [19].

In our study, conducted on Greek skulls, the incidence of WBs presence $(74.7 \%)$ is remarkably high. A similar high incidence (80.32\%) was reported in Chinese [5], whereas in West Anatolian and Eastern Indian skulls, the reported incidences were $59.3 \%$ 


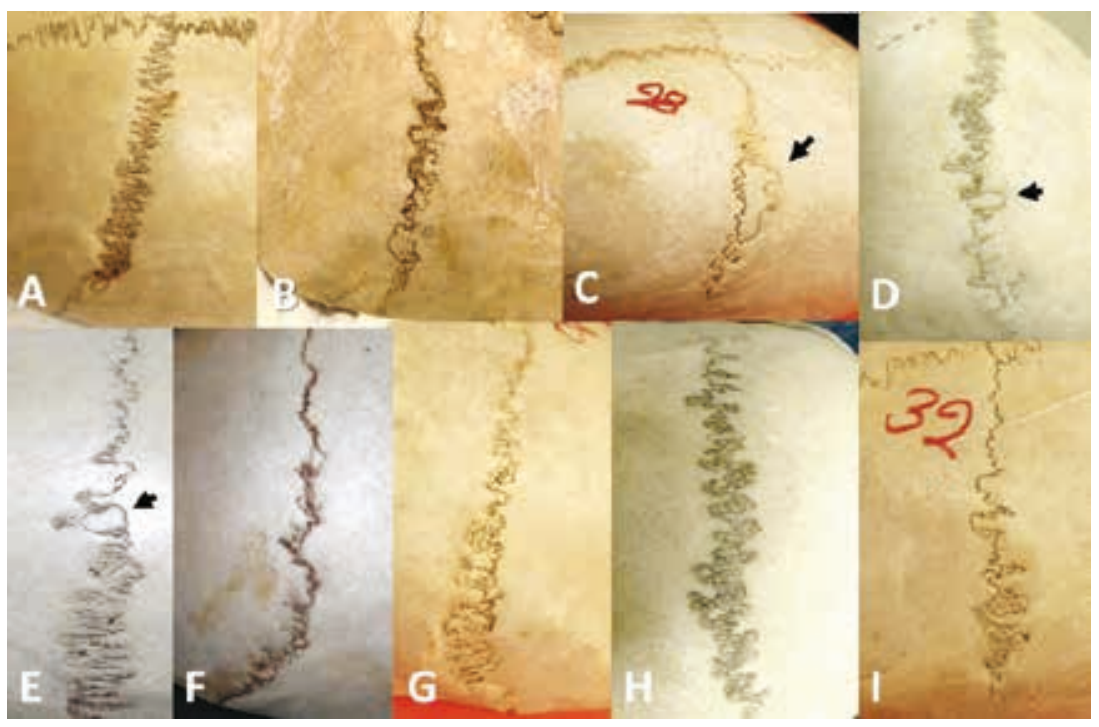

Figure 3. A-I. Wormian bones located into the coronal suture.

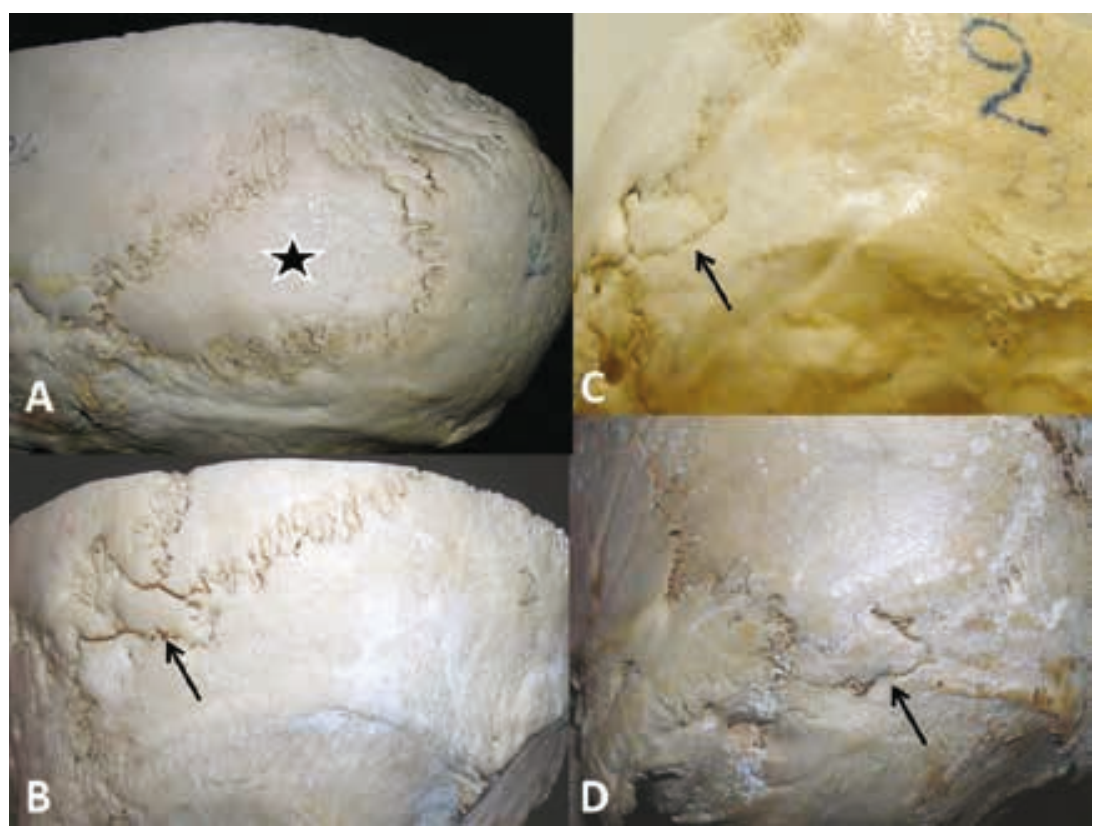

Figure 4. Wormian bones (WBs) in the area of asterion (black arrows) (A-D); A. Enlarged WB (asterisk).

and $45 \%$, respectively $[8,14]$. The lowest incidence (9\%) was reported by Govsa et al. [15] in Turkish skulls. Cirpan et al. [8] along with current study highlighted a stronger number of multiple WBs found in skulls (44.6\% and $39.3 \%$, respectively). A wide variability in the occurrence of WBs among different ethnic groups is a reality [3]. On the other hand, WBs most commonly located is the LS, among different populations. In the present study, WBs most commonly appear in the LS (44.6\%), similarly to Edwards and co-authors' study [10]. Murlimanju et al. [23, 24] reported that WBs are found along the LS in $56.4 \%$. In our study, the second most common location was the CS followed by asterion, PMS, SQS and pterion. Several authors [23, 24, 27] found the asterion, as the second most common location, while Nayak [25] reported the epipteric bone, as the second most common location. Cirpan et al. [8] mentioned that WBs appear in order of frequency in LS ( $40.7 \%$ on the left and $37.3 \%$ on the right side), pterion ( $8 \%$ on the left side), asterion, SQS, lambda, SS, CS, OCMS and bregma. In another study [31], WBs were identified in LS (50\%), CS (25\%), within fontanelles in asterion, PF and AF and into the orbit. In skulls with sagittal synostosis, the incidence of WBs in the AF was 


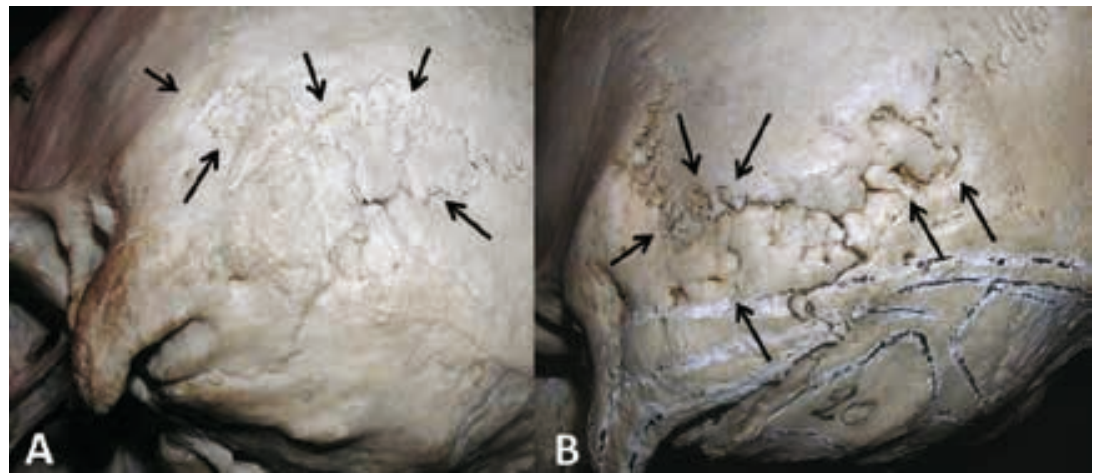

Figure 5. A, B. Wormian bones into the parietomastoid and lambdoid sutures (black arrows).

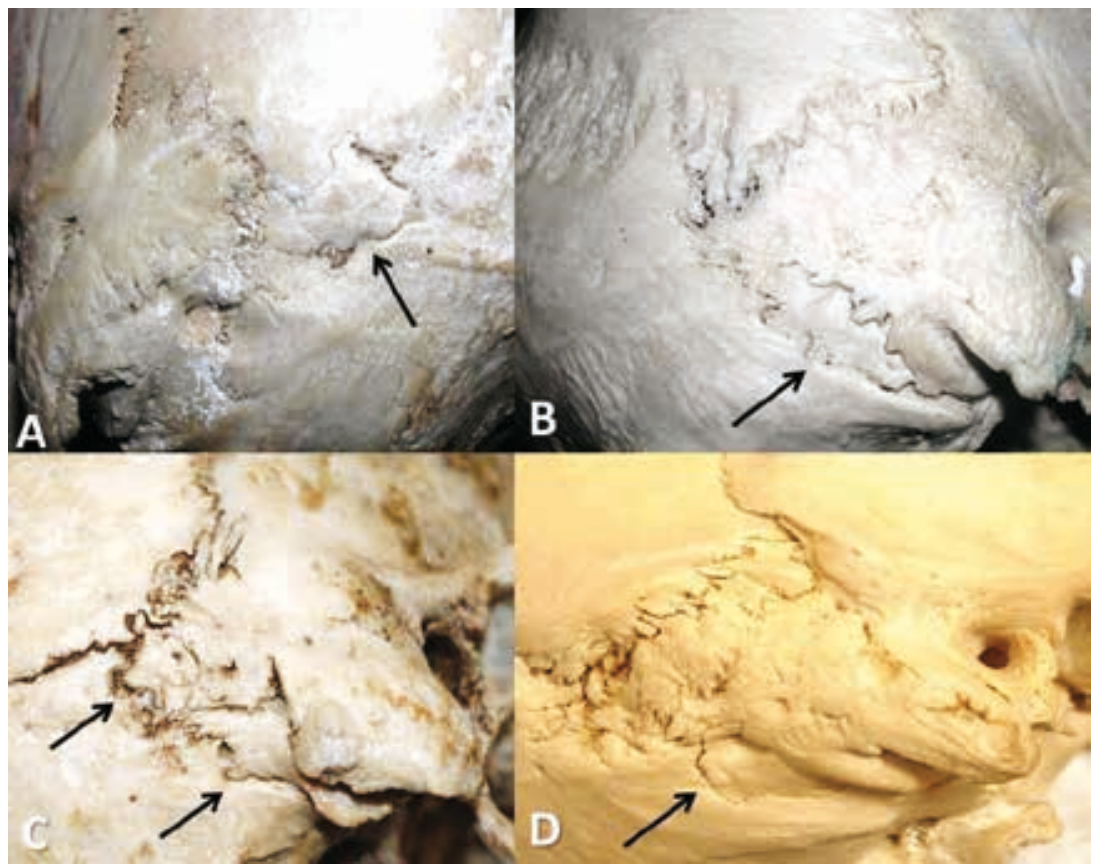

Figure 6. A-D. Wormian bones in the occipitomastoid suture (black arrows).

reported in 4\% [1]. Sanchez-Lara et al. [31] and Jeanty et al. [18] showed that WBs were more frequently observed on the right side of the skulls, contrariwise to Cirpan et al. [8] who reported that WBs appear more often on the left side. Both genders had a similar incidence of WBs [16].

In the present study, it is worth mentioning that the shape, number and even location of WBs differ between outer and inner tables of the skull. In all examined cases, WBs were smaller and sutures were less complicated intracranially. It is suggested that WBs are isolated bones formed by an inner and outer plate. An interesting point of the current study was that the inner plate of the bones did not correspond to the outer one. Specifically, even though intracranial and exocranial WBs appeared at the same sutures, their exact location and number mismatch. Also in the current study, no gender dimorphism was observed with respect to overall incidence, but regarding location, a male predominance was found in $L S$ and OCMS. This result differs from Patil and Sheelavant [27] findings, which reported a female predominance in LS and SS in the area of lambda. Deformation induced by certain customs directly affecting the cranial shape, are termed as "cultural cranial deformation" and ultimately influence the number of WBs [11]. A probable explanation of deformation is the continuously exerted pressure on the front and back of the infant's cranium, resulting 


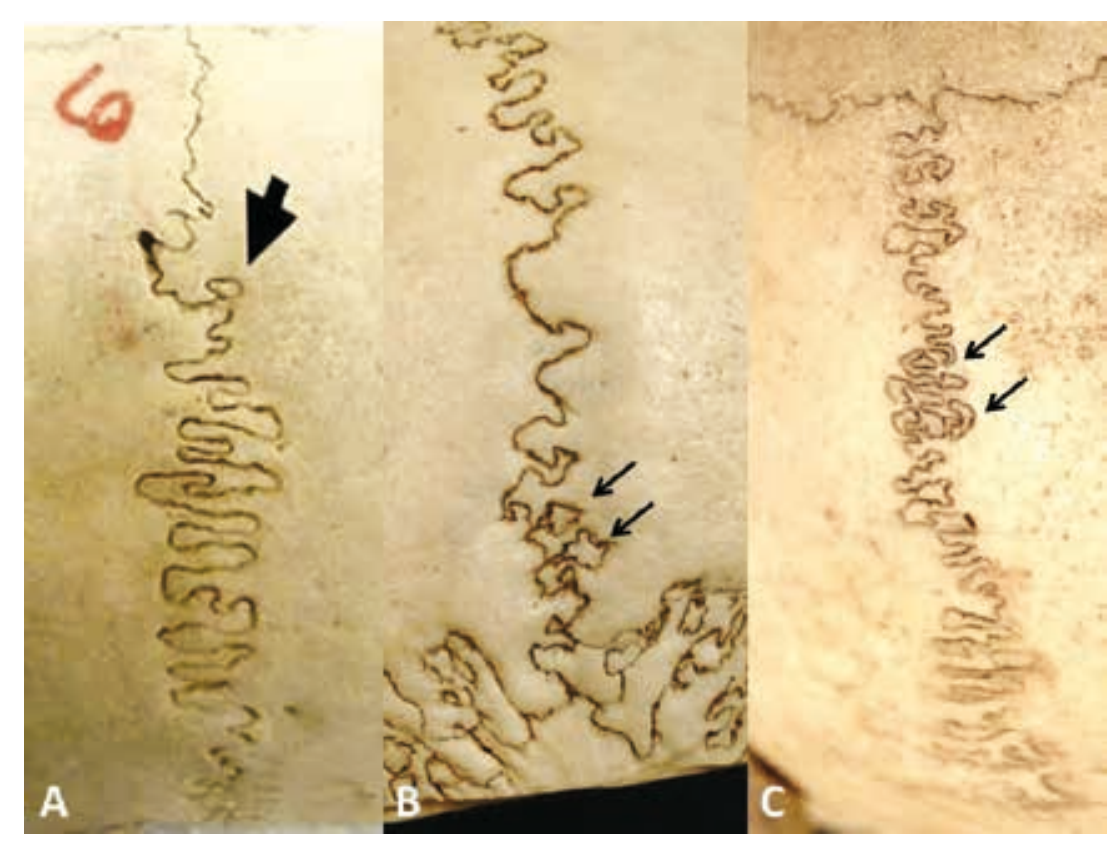

Figure 7. A-C. Wormian bones into the sagittal suture (thick and thin arrows).

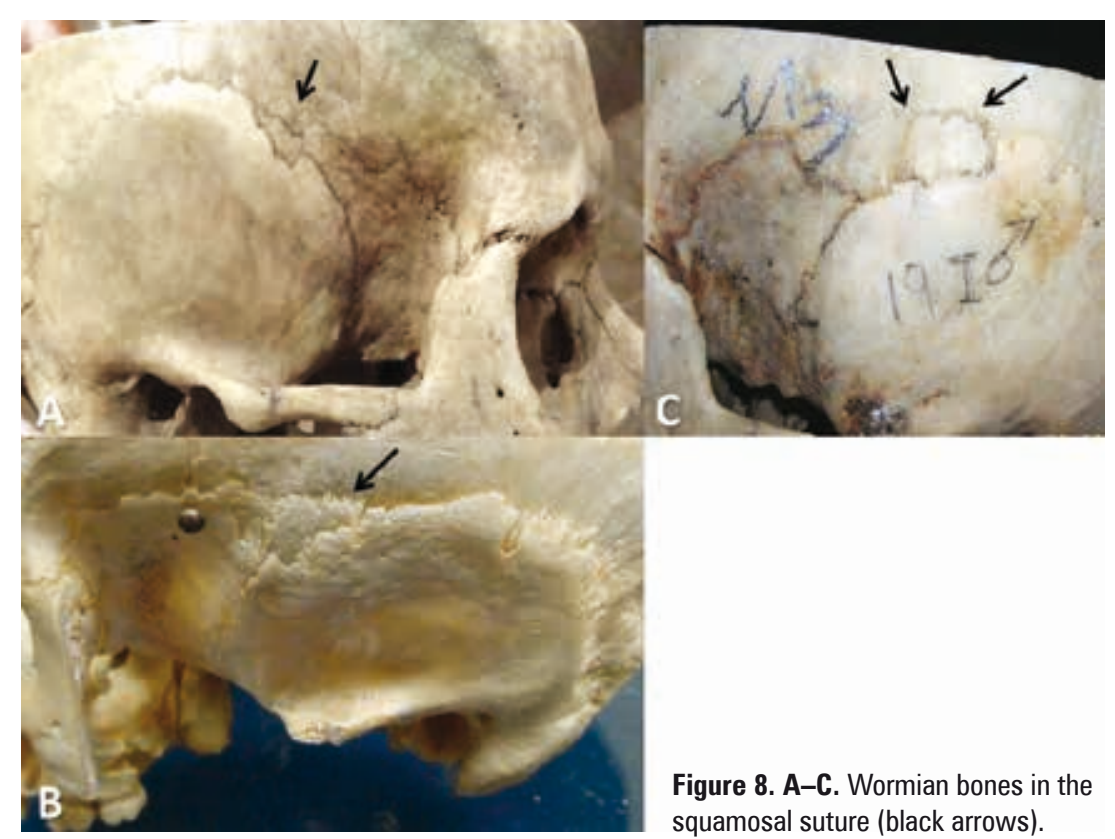

in a pronounced frontal and occipital flattening and an increase in cranial height [33]. El-Najjar and Dawson [11] concluded that the occurrence of lambdoid WBs was genetically controlled. Bennett [4] correlated WBs in posterior vault with basi-occipital length and concluded that stresses connected with higher measurements caused WBs formation. Barberini et al. [2] supported that WBs formation may be controlled by a number of genes with additive action.
Wormian bones may be clinically important signs for silent pathologies. They are most commonly smaller and less numerous in normal than pathologic variant [19]. Bennet [4] explained that WBs may develop due to rapid cerebral expansion, and this is why they are found in higher numbers in hydrocephalic patients. Nowadays, plagiocephaly is correlated with asymmetry due to pressure and a higher number of WBs. It is demonstrated that the deformed crania have 


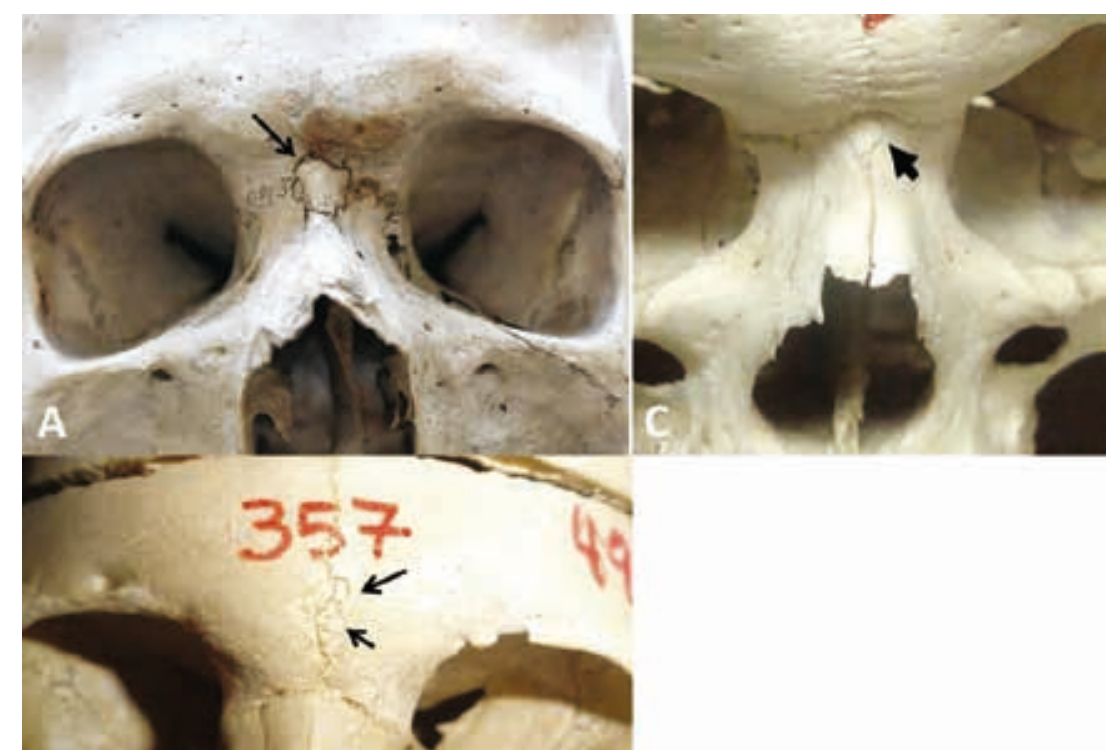

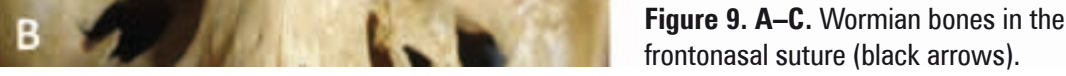

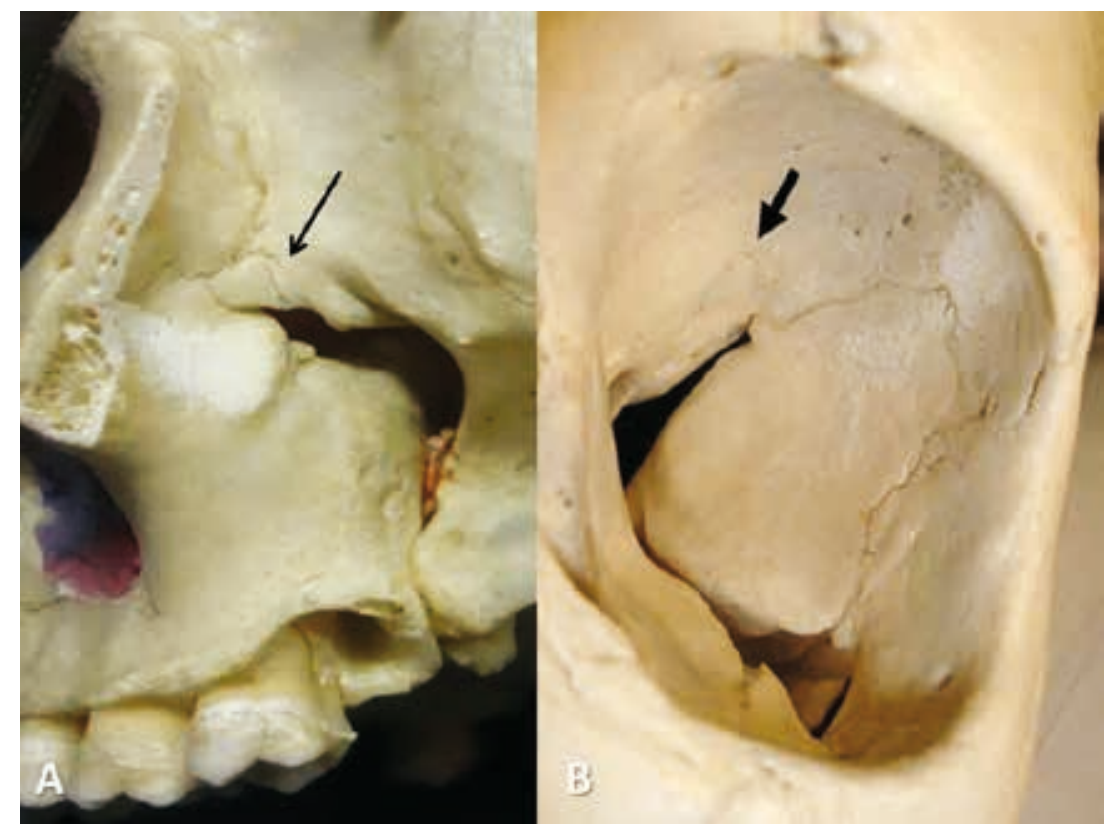

Figure 10. A, B. Wormian bones in sphenofrontal suture (top of the pterygopalatine fossa) and into the orbit (black arrows).

a higher number of WBs than the undeformed, and most WBs have been located in an antero-posteriorly oriented deformation [31]. WBs in more posteriorly placed sutures are more prone to environmental factors in comparison to their more anteriorly placed counterparts which are under stronger genetic control [31]. WBs presence is associated with abnormal central nervous system development (microcephaly, macrocephaly, hydrocephalus, craniosynostosis, cerebral palsy, epilepsy and learning difficulties) and this may be a sign of early identification and treatment in affected paediatric population [29]. Moreover, their presence is particularly higher in non-symmetrical skulls with metopism [8]. Cirpan et al. [9] reported a strong correlation between WBs coexistence and metopism, explaining that the factors leading to metopism may also form WBs.

Wormian bones are clinically important markers for many pathological entities. Though common in adults, their occurrence in children can be associated with a plethora of pathological entities such as 


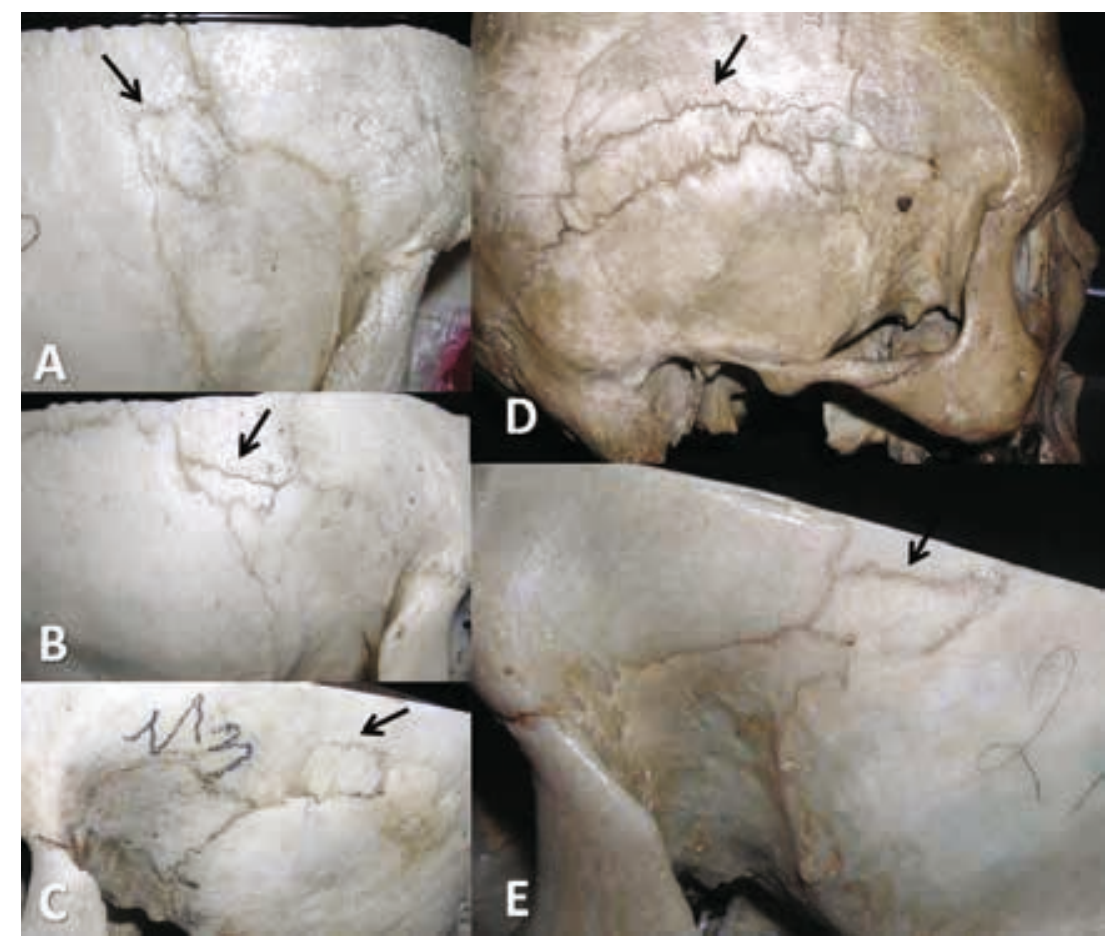

Figure 11. Wormian bones in the area of pterion (right-sided: A, B, D and left-sided: C, E) (black arrows).

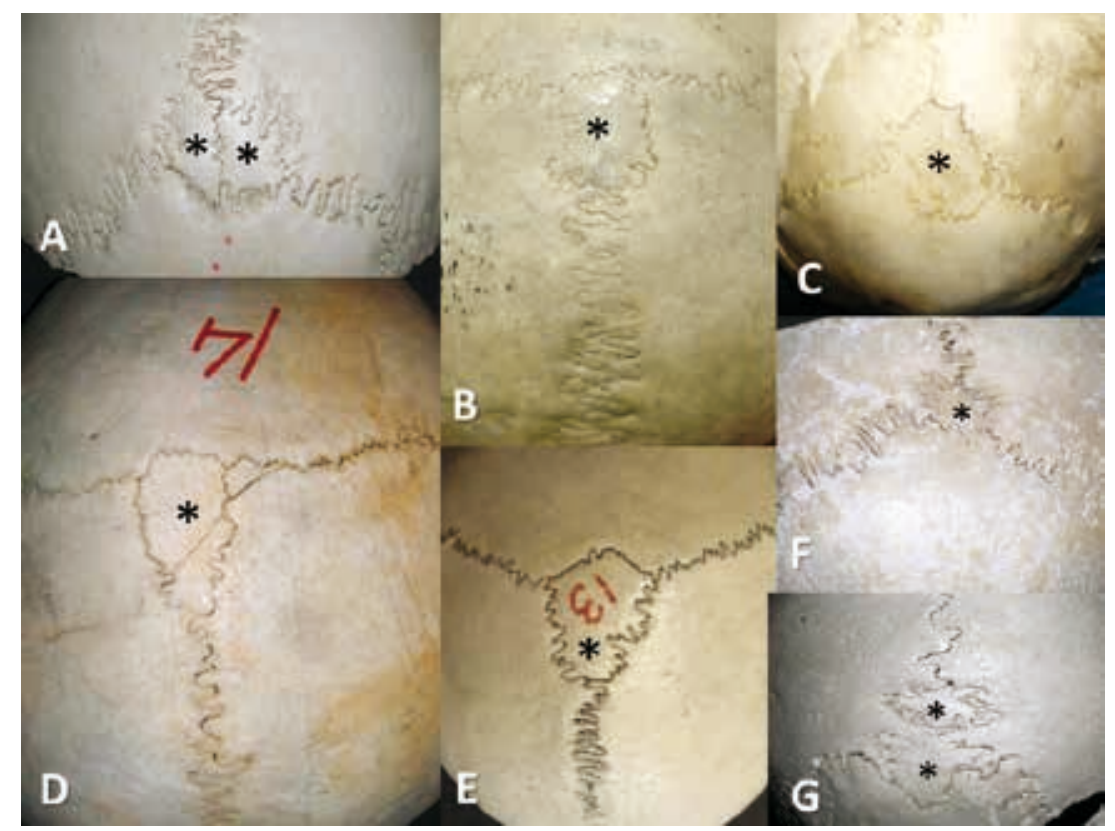

Figure 12. Wormian bones in bregma (B, D, E) and posterior fontanelle (A, C, F, G) (asterisks).

Rickets syndrome, "Kinky-hair" Menke's syndrome, Otopalatodigital syndrome, Hajdu-Cheney syndrome (platybasia and WBs, osteoporosis with fractures, and acro-osteolysis), acrocallosal syndrome (facial dysmorphism and midline abdominal defects), Down's syndrome, cleidocranial dysostosis, pycnodysostosis, hypoparathyroidism, hypophosphatasia and osteogenesis imperfecta $[20,22,30,32]$. Mutations of stable proteins may lead to a skeletal homeostasis disorder and WBs appearance [7].

Wormian bones are of diagnostic value, since their presence may be occasionally misinterpreted 


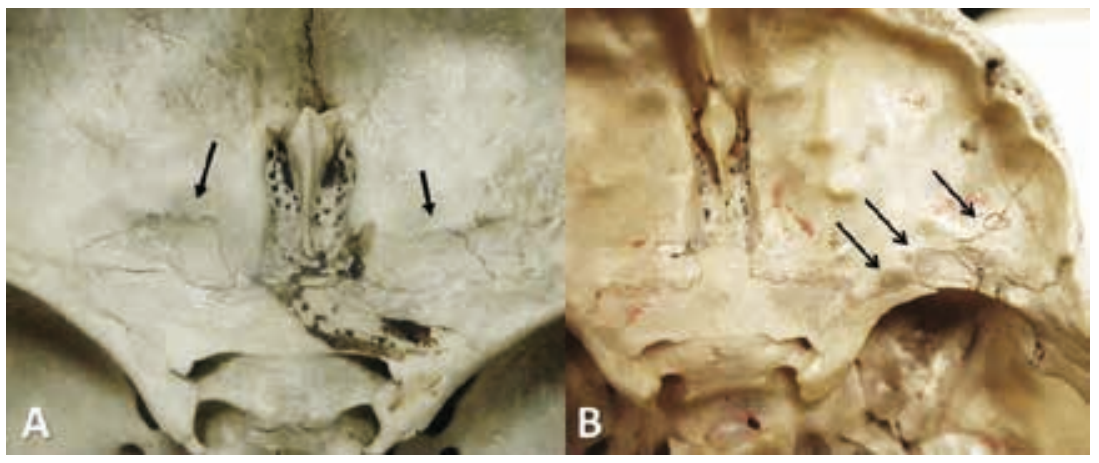

Figure 13. Wormian bones intracranially at the frontal (A) and sphenoid bones (B).

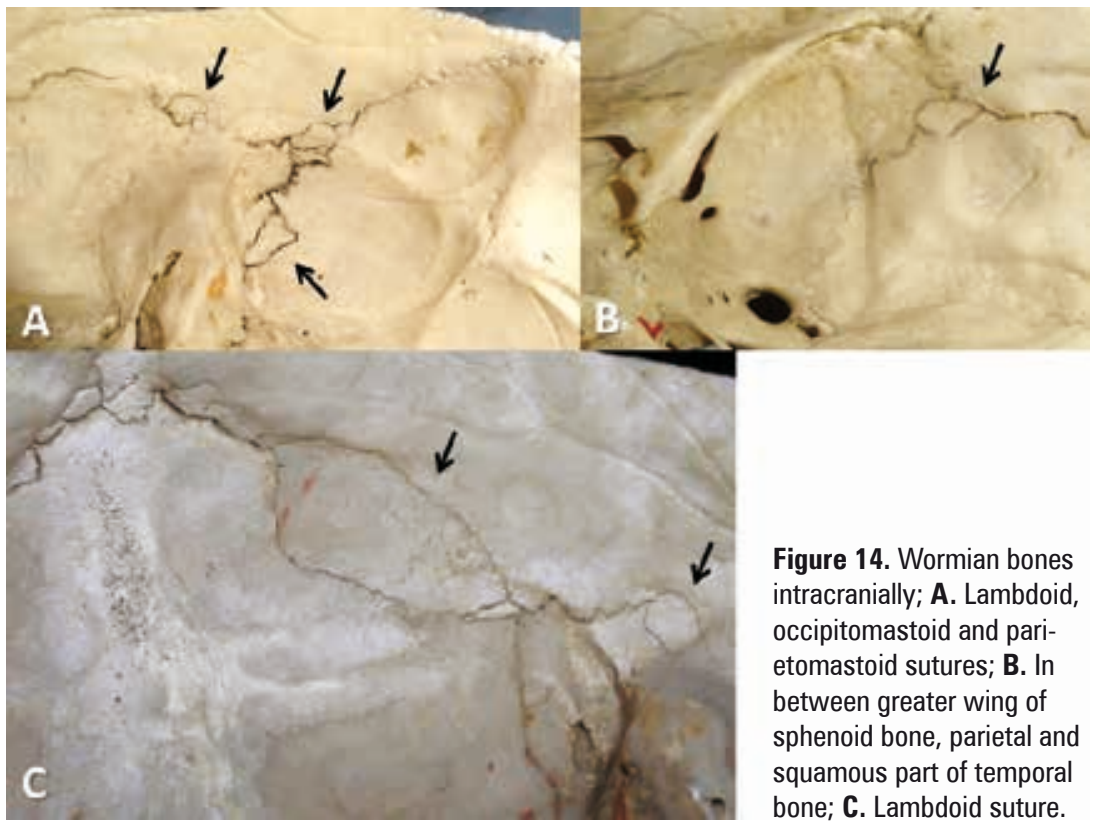

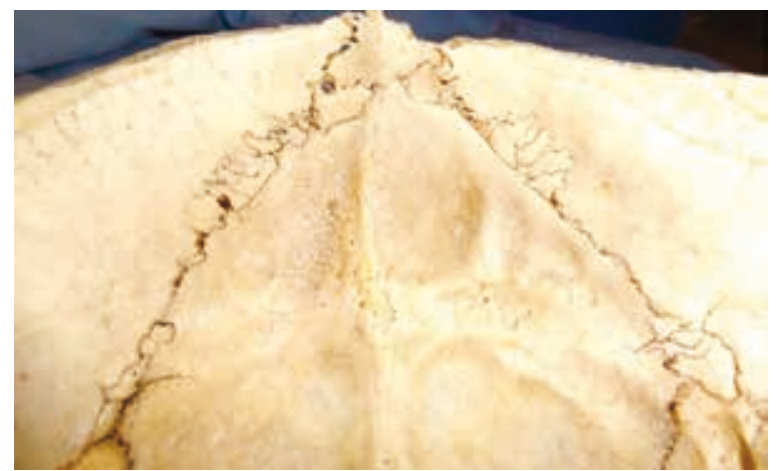

Figure 15. Multiple Wormian bones intracranially at the lambdoid suture.

as fractures during radiological examination [11]. WBs morphological and topographical details are of paramount importance from the medico-legal point of view in forensic investigation of non-accidental skull injuries in order to rule out physical abuse and brittle bones [15]. In some cases, the traumatic lesion of a gunshot entry wound of the skull, may have similarities with the orifice of a WB, thus emphasis must be given on differential diagnosis during routine anthropological examination. Neurosurgeons should be cautious when performing burr holes over the pterion, since presence of WBs may lead to complications [12].

Limitations of the study were: (i) The sample did not include infant skulls and skulls with syndromic background and asymmetries, or pathological skulls so we could not investigate the effect of these variants in WBs appearance; (ii) Due to the small number of skulls with inca bones we could not detect any possible correlation between WBs and inca bones; 
(iii) WBs shape was not investigated; (iv) A small number of skulls was craniotomised, as all bones were part of the osteological collection of our Institutions.

\section{CONCLUSIONS}

The current study highlights a high incidence of WBs in a Greek population, indicating ethnical variation. The knowledge of frequency, number and exact location of WBs is essential for anthropologists, any physician involved in diagnosis and treatment of skull area pathologies and forensic specialists investigating child abuse suspicious cases.

\section{Acknowledgements}

This study has not received any funding support. Miss Elpida Repousi contributed to this work.

\section{REFERENCES}

1. Agrawal D, Steinbok P, Cochrane DD. Pseudoclosure of anterior fontanelle by wormian bone in isolated sagittal craniosynostosis. Pediatr Neurosurg. 2006; 42(3): 135-137, doi: 10.1159/000091854, indexed in Pubmed: 16636612.

2. Barberini $F$, Bruner E, Cartolari R, et al. An unusually-wide human bregmatic Wormian bone: anatomy, tomographic description, and possible significance. Surg Radiol Anat. 2008; 30(8): 683-687, doi: 10.1007/s00276-008-0371-0, indexed in Pubmed: 18523715.

3. Bellary SS, Steinberg A, Mirzayan N, et al. Wormian bones: a review. Clin Anat. 2013; 26(8): 922-927, doi: 10.1002/ca.22262, indexed in Pubmed: 23959948.

4. Bennett KA. The etiology and genetics of Wormian bones. Am J Phys Anthropol. 1965; 23(3): 255-260, indexed in Pubmed: 5861223.

5. Brothwell DR. The use of non-metrical characters of the skull in differentiating populations. Dt Ges Anthrop. 1958; 6: 103-109.

6. Burrows AM, Caruso KA, Mooney MP, et al. Sutural bone frequency in synostotic rabbit crania. Am J Phys Anthropol. 1997; 102(4): 555-563, doi: 10.1002/(SICI)10968644(199704)102:4<555::AID-AJPA9>3.0.CO;2-Q, indexed in Pubmed: 9140544.

7. Canalis E, Zanotti S. Hajdu-Cheney syndrome, a disease associated with NOTCH2 mutations. Curr Osteoporos Rep. 2016; 14(4): 126-131, doi: 10.1007/s11914-016-0311-6, indexed in Pubmed: 27241678.

8. Cirpan S, Aksu F, Mas N. The incidence and topographic distribution of sutures including wormian bones in human skulls. J Craniofac Surg. 2015; 26(5): 1687-1690, doi: 10.1097/ SCS.0000000000001933, indexed in Pubmed: 26114515.

9. Cirpan $S$, Aksu F, Mas N, et al. Coexistence of Wormian bones with metopism, and vice versa, in adult skulls. J Craniofac Surg. 2016; 27(2): 493-495, doi: 10.1097/SCS.0000000000002370, indexed in Pubmed: 26845093.

10. Edwards B, Wang JMh, Iwanaga J, et al. Hiding within the cracks: case report of rare sutural bone found at the nasion. Cureus. 2017; 9(6): e1333, doi: 10.7759/cureus.1333, indexed in Pubmed: 28698833.

11. El-Naijar M, Dawson GL. The effect of artificial cranial deformation on the incidence of Wormian bones in the lambdoidal suture. Am J Phys Anthropol. 1977; 46(1): 155-160, doi: 10.1002/ ajpa.1330460119, indexed in Pubmed: 835687.

12. Ersoy M, Evliyaoglu C, Bozkurt MC, et al. Epipteric bones in the pterion may be a surgical pitfall. Minim Invasive Neurosurg. 2003; 46(6): 363-365, doi: 10.1055/s-2003-812434, indexed in Pubmed: 14968406.

13. Finkel DJ. Wormian bones - a study of environmental stress. Am J Physical Anthropol. 1971; 35: 278.
14. Ghosh SK, Biswas S, Sharma S, et al. An anatomical study of wormian bones from the eastern part of India: is genetic influence a primary determinant of their morphogenesis? Anat Sci Int. 2017; 92(3): 373-382, doi: 10.1007/s12565-016-0342-1, indexed in Pubmed: 27038026.

15. Govsa F, Ozer MA, Bayraktaroglu S, et al. Anatomoradiological identification of intrasutural bones for importance of cranial fracture. Turk Neurosurg. 2014; 24(3): 357-362, doi: 10.5137/10195149.JTN.8380-13.2, indexed in Pubmed: 24848174.

16. Hanihara $T$, Ishida $H$. Frequency variations of discrete cranial traits in major human populations. I. Supernumerary ossicle variations. J Anat. 2001; 198(Pt 6): 689-706, indexed in Pubmed: 11465862

17. Hauser G, De St. Epigenetic variants of the human skull. Stuttgart: Schweizerbart. Actas del XVII Congreso Internacional de Americanistas, Buenos Aires. 1989.

18. Jeanty P, Silva SR, Turner C. Prenatal diagnosis of wormian bones. J Ultrasound Med. 2000; 19(12): 863-869, indexed in Pubmed: 11127012.

19. Kaplan SB, Kemp SS, Oh KS. Radiographic manifestations of congenital anomalies of the skull. Radiol Clin North Am. 1991; 29(2): 195-218, indexed in Pubmed: 1998047.

20. Kumar A, Rajesh B, Arumugam K, et al. Sutural bones associated with lambdoid suture of human skull: presence, variations and clinical importance. Int J Anat Res. 2016; 4(2.2): 2331-2336, doi: 10.16965/ijar.2016.208.

21. Mao JJ, Wang X, Mooney MP, et al. Strain induced osteogenesis of the craniofacial suture upon controlled delivery of low-frequency cyclic forces. Front Biosci. 2003; 8: a10-a17, indexed in Pubmed: 12456317.

22. Marti B, Sirinelli D, Maurin L, et al. Wormian bones in a general paediatric population. Diagn Interv Imaging. 2013; 94(4): 428-432, doi: 10.1016/j.diii.2013.01.001, indexed in Pubmed: 23352712. Muralimanju BV, Prabhu LV, Ashraf CM, et al. Morphological and topographical study of Wormian bones in cadaver dry skulls. J Morphol Sci. 2011; 28: 176-179.

23. Murlimanju BV, Gupta C, Samiullah D, et al. Morphological investigation of cranial sutures in Indian human adult skulls. Rom J Morphol Embryol. 2011; 52(3 Suppl): 1097-1100, indexed in Pubmed: 22119831.

24. Nayak S. Presence of Wormian bone at bregma and paired frontal bone in an Indian skull. Neuroanatomy. 2006; 5: 42-43.

25. O'Loughlin VD. Effects of different kinds of cranial deformation on the incidence of wormian bones. Am J Phys Anthropol. 2004; 123(2): 146-155, doi: 10.1002/ajpa.10304, indexed in Pubmed: 14730648.

26. Patil M, Sheelavant S. Sexual Dimorphism among the Wormian Bones In Adult Human Skulls. J Indian Acad Forensic Med. 2012(2): 124-127.

27. Piagkou M, Skotsimara G, Repousi E, et al. Enlarged parietal foramina: a rare finding in a female Greek skull with unusual multiple Wormian bones and a rich parietal vascular network. Anat Sci Int. 2013; 88(3): 175-180, doi: 10.1007/s12565-0130173-2, indexed in Pubmed: 23543411.

28. Pryles CV, Khan AJ. Wormian bones. A marker of CNS abnormality? Am J Dis Child. 1979; 133(4): 380-382, indexed in Pubmed: 433853.

29. Reid TH, Tam A, Antoniou G, et al. Anterior fontanelle Wormian bone with exomphalos major and dysmorphic facial features: a previously unseen association? J Craniofac Surg. 2016; 27(7): 1799-1801, doi: 10.1097/SCS.0000000000002962, indexed in Pubmed: 27513767.

30. Sanchez-Lara PA, Graham JM, Hing AV, et al. The morphogenesis of wormian bones: a study of craniosynostosis and purposeful cranial deformation. Am J Med Genet A. 2007: 143A(24): 3243-3251, doi: 10.1002/ajmg.a.32073, indexed in Pubmed: 18000970 .

31. Shah AB, Tisano BK, Elattar O, et al. Foot deformities in hajducheney syndrome: a rare case report and review of the literature. J Orthop Case Rep. 2017; 7(5): 11-15, doi: 10.13107/ jocr.2250-0685.876, indexed in Pubmed: 29242787.

32. Tubbs RS, Salter EG, Oakes WJ. Artificial deformation of the human skull: a review. Clin Anat. 2006; 19(4): 372-377, doi: 10.1002/ca.20177, indexed in Pubmed: 16092127. 